\title{
Ciclo de vida turístico de uma comunidade litorânea: o caso de Pontal de Coruripe (AL)
}

\section{Tourist life cycle of a sea-side place: the case of Pontal de Coruripe (AL, Brazil)}

\author{
Priscylla Maria Ferreira da Silva, Lindemberg Medeiros de Araujo, \\ Silvana Pirillo Ramos
}

RESUMO: O turismo, como fenômeno socioespacial baseado nos deslocamentos humanos, é motivado principalmente pelo consumo de paisagens. Ao se instalar em um determinado lugar, o turismo desencadeia diversas transformações econômicas, sociais, culturais e ambientais. Fatores internos e externos interferem no ciclo de desenvolvimento dos lugares turísticos. A adequação das tipologias turísticas à realidade local e a forma de gestão da atividade, considerando as características singulares de cada paisagem, são os fatores centrais que determinam os tipos de efeitos que serão ocasionados. Para as populações receptoras os efeitos do turismo são diretos uma vez que a atividade dinamiza o cotidiano local. Este trabalho tem como recorte espacial de análise 0 povoado Pontal de Coruripe, localizado no município de Coruripe, litoral sul alagoano. Conhecido pelo artesanato em palha de ouricuri e por suas belezas naturais, como todo espaço receptivo Pontal de Coruripe sofre as influências decorrentes da sua turistificação. Este estudo tem como objetivo compreender a constituição e desenvolvimento do Pontal do Coruripe como lugar turístico, por meio da caracterização de seu ciclo de vida turístico. O modelo do ciclo de vida do lugar turístico, conhecido na literatura internacional pela sigla TALC (Tourism Area Life Cycle), foi publicado por Richard W. Butler, em 1980, e desde então vem sendo utilizado para o estudo de destinações, lugares ou atrativos turísticos, visando identificar o estágio atual em que o objeto estudado se encontra e, por conseguinte, a visualização da trajetória passada e possíveis caminhos futuros. $O$ ciclo de vida de Pontal de Coruripe foi analisado a partir das dimensões econômica e social, considerando o recorte temporal que se estende desde o período anterior à chegada do turismo ao lugar, antes de 1985, até o ano de 2015. O trabalho se caracteriza como um estudo de caso com abordagem metodológica qualitativa. Os sujeitos da pesquisa são os gestores dos meios de hospedagem. Os dados foram coletados através de entrevistas com roteiros semiestruturados, observação direta, levantamento fotográfico e pesquisa documental. O trabalho apresenta o histórico da oferta de unidades habitacionais no destino, as características do seu ciclo de vida, assim como as expectativas relacionadas ao futuro do turismo em Pontal de Coruripe.

PALAVRAS-CHAVE: Turismo; Destino; Ciclo de Vida; Alagoas. 


\section{ABSTRACT}

As a socio-spatial phenomenon based on leisure travel, tourism is motivated mainly by the consumption of landscapes. When tourism is inserted in a place it unleashes a change process with economic, social, cultural and environmental consequences. Both internal and external factors influence a place's tourism development cycle. Tourism typologies adapted to local characteristics and the management approach in accordance with the singular characteristics of each landscape are the key factors determining the types of caused effects. Tourism development causes direct impacts on host communities as tourist activities change the daily local socio-economic dynamics. This work focuses on Pontal de Coruripe, a community of the municipality of Coruripe which is located in the south littoral of the Alagoas state, Brazil. Pontal de Coruripe, known for its handicraft made from leaves of the ouricuri palm tree as well as for its beautiful natural characteristics, is affected by its touristification. The objective of this study is to understand the formation and development of Pontal de Coruripe as a tourist place on the basis of its tourist area life cycle.The model of the tourist area life cycle (TALC) was developed by Richard W. Butler and published in 1980, and since then it has been widely used to study tourist destinations, places and attractions with the aim of identifying the stage in which a tourist area is placed, thus understanding its historical development and the possible ways in which it may develop from then. Pontal de Coruripe's TALC was analyzed with a focus on its economic and social dimensions, since before touristification started - prior to 1985 - up until when this study was implemented, in 2015. The research was developed as a case study using a qualitative methodological approach. Data collection used a semi-structured interview schedule which was run with hotel managers as well as observation, a photographic survey and document perusal. Results present the historical development of the offer of hotel rooms in Pontal de Coruripe, the characteristics of its TALC, as well as the expectations as to how tourism may develop into the future in this community.

KEYWORDS: Tourism; Destination; Life Cycle; Alagoas.

\section{Introdução}

O turismo é uma atividade dinâmica que ao se espacializar cria possibilidades de desenvolvimento, que variam de acordo com as singularidades dos lugares, somadas às formas de gestão que são adotadas pelos atores que se relacionam com a atividade, isto é, a iniciativa privada, o poder público, os próprios turistas e as populações receptoras.

Assim, o turismo traz múltiplas implicações para os espaços nos quais se insere, especialmente para as localidades receptoras, que ao mesmo tempo em que sofrem impactos negativos também são beneficiárias de resultados positivos, como a valorização do patrimônio cultural local, diversificação das atividades econômicas, geração de emprego e incremento de renda, aumento da oferta de serviços e melhoria na infraestrutura.

Por causa desses benefícios, a atividade turística vem sendo estimulada na maior parte dos países pelo poder público, o que é aproveitado por empreendedores que percebem novas oportunidades de investimento que o estímulo ao turismo propicia. No Brasil, há décadas, existem políticas 
públicas específicas que têm como meta o desenvolvimento da atividade, como os planos nacionais de turismo (2003-2007, 2007-2010 e 2013-2016), o Programa Regional para o Desenvolvimento do Turismo (Prodetur), dentre outras políticas (ARAUJO e DREDGE, 2012). O interesse do governo no fomento do turismo como uma alternativa de desenvolvimento já data de mais de cinco décadas, como identificado abaixo:

\begin{abstract}
Na década de 1960, quando o poder público começou a se preocupar com o turismo e vislumbrar nessa atividade uma alternativa de emprego e renda, o mar passou a ser mais explorado como área de lazer. No Nordeste, sobretudo a partir da década de 1980, começou-se a investir em infraestrutura no sentido de atrair visitantes nacionais e estrangeiros (FONTELES, 2004, p. 37).
\end{abstract}

Nesse cenário, enquadra-se o recorte espacial deste estudo - o povoado Pontal de Coruripe, município de Coruripe $(A L)$, que teve o início da implantação de sua estrutura de hospedagem na década de 1980. Localizado no litoral sul alagoano, o município de Coruripe, assim como todo o litoral de Alagoas, tem seu território marcado pela influência do turismo. Apesar de se ter propostas que buscam viabilizar o desenvolvimento do setor em outras regiões, particularmente através do Programa de Regionalização do Turismo (PRT), em Alagoas, a atividade turística é historicamente mais difundida no litoral, que com base na política do Ministério do Turismo (MTur), subdivide-se em três regiões turísticas: a Região Metropolitana, o Polo Costa dos Corais (litoral Norte) e o Polo Lagoas e Mares do Sul (litoral Sul).

O polo Lagoas e Mares do Sul, com apelo centrado nos recursos naturais, como as lagunas e coqueirais existentes na região, possui estrutura de hospedagem composta por empreendimentos do tipo hotéis, pousadas e residências secundárias. Nesse contexto, se insere o município de Coruripe.

A natureza caprichou em Coruripe. O mar exuberante e coqueiros em profusão realçam o lugar. O município tem belas praias, destacando-se Lagoa do Pau, Miaí de Cima, Miaí de Baixo. Cada qual se destaca pela singularidade de suas belezas como é o caso do Pontal de Coruripe, que tem sua marca registrada desde 1948, quando se construiu um farol para orientar as embarcações. O Pontal é um povoado de pescadores que se transformou num atraente destino turístico (SEDETUR-AL, 2015).

Conhecido pelo artesanato em palha da palmeira Ouricuri (Syagrus coronata (Mart.) Becc.), e por suas belezas naturais, como todo espaço receptivo Pontal de Coruripe apresenta peculiaridades ao longo do seu processo de turistificação. Este estudo tem por objetivo compreender a constituição e desenvolvimento do Pontal do Coruripe como lugar turístico, 
por meio da caracterização de seu ciclo de vida turístico. Buscou-se compreender quando e como Pontal de Coruripe surgiu como lugar turístico e como ele se desenvolveu ao longo do tempo, identificando-se as características de seu ciclo evolutivo.

O modelo do ciclo de vida do lugar turístico, conhecido na literatura internacional pela sigla TALC (Tourist Area Life Cycle), foi publicado por Richard W. Butler, em 1980. Desde então, vem sendo utilizado para o estudo de destinações, lugares ou atrativos turísticos, visando se compreender 0 desenvolvimento dos destinos desde o período no qual eles começaram a receber os primeiros visitantes até o presente.

O ciclo de vida de Pontal de Coruripe foi analisado com base nas dimensões econômica e social, tendo-se como referência o recorte temporal que se estende desde o período anterior à chegada do turismo ao lugar, antes de 1985, até o ano de 2015.

O trabalho, que faz parte de uma investigação mais ampla, se caracteriza como um estudo de caso exploratório e descritivo, com abordagem qualitativa. Além da análise da demanda, o estudo do ciclo de vida turístico de um determinado lugar frequentemente envolve 0 levantamento da evolução temporal do setor de hospedagem, expresso pelo número de unidades habitacionais. Para a composição de tal histórico foram realizadas 11 entrevistas utilizando-se roteiros semiestruturados, direcionados aos gestores e/ou representantes de todos os meios de hospedagem ativos e inativos de Pontal de Coruripe. Para referenciar as opiniões e declarações dos pousadistas, atribuiu-se aleatoriamente códigos que vão do P1 ao P11.

A realização de observação, levantamento fotográfico e pesquisa documental, também compuseram o quadro de ferramentas de pesquisa deste estudo, possibilitando a coleta de dados de aspectos do TALC de Pontal de Coruripe, como a oferta de serviços públicos e a caracterização dos empreendimentos de hospedagem.

\section{Pontal de Coruripe}

Distante 90 km de Maceió, e com área territorial de 898,625 km² (IBGE, 2015), o município de Coruripe é um dos maiores do Estado de Alagoas. Com uma economia historicamente marcada pela cultura da cana-de-açúcar, possui a maior área agrícola e o maior canavial do Estado (ENCICLOPÉDIA..., 2012, p. 302). Segundo Diegues (2006, p. 84), historicamente "os engenhos vieram a criar-se nas vizinhanças do rio Coruripe e do Poxim; esta área tornou-se açucareira, servida por excelente e rico vale: o do Coruripe".

A Usina Coruripe é destaque nacional no setor sucroalcooleiro e energético, com a matriz no município de Coruripe e quatro filiais no Estado de Minas Gerais, consequentes da expansão iniciada na década de 1990. É "[...] uma empresa de capital fechado, cujo desenvolvimento transformou um pequeno engenho de açúcar em uma das mais importantes corporações empresariais do Brasil' (USINA CORURIPE, 2015). 
Com a crise do setor sucroalcooleiro no Estado de Alagoas em décadas recentes, ocorreu a desativação de uma das três usinas do município de Coruripe, no ano de 2013 (Usina Guaxuma - grupo João Lyra), fato que indubitavelmente altera o quadro da economia local. No entanto, resta-Ihe a Usina Pindorama (implantada no ano de 2003) e a tradicional Usina Coruripe. Além da histórica e predominante cultura da cana-de-açúcar em Coruripe, nesse município encontra-se relativa diversidade agrícola, com produção de coco-da-baía, feijão, maracujá e outros (IBGE, 2015).

Com $56 \mathrm{~km}$ de litoral, Coruripe conta com um atrativo cenário formado por praias e outras características físico-naturais; por exemplo, os coqueirais estão presentes em praticamente todo o trecho litorâneo do município. Além disso, cada parte de seu território se evidencia pelas singularidades de seus traços culturais, como a manifestação cultural Mané do Rosário, genuinamente coruripense, autêntica do povoado Poxim (SILVA, 2013). O município é composto pelos povoados Pindorama, Poxim (que são distritos), Lagoa do Pau, Pontal de Coruripe, Barreiras, Miaí de Cima, Miaí de Baixo, além de outros menores, que junto à sede, somam uma população de 56.631 habitantes (IBGE, 2015).

Atualmente, Pontal de Coruripe dispõe de nove meios de hospedagem, do tipo pousadas, que reúnem 102 unidades habitacionais, ofertando 335 leitos ${ }^{1}$. Esses empreendimentos são caracterizados por distintos estilos, sendo todos de pequeno porte, possuindo de cinco a 20 unidades habitacionais cada um. A localização próxima ao mar é outra característica em comum, o que trouxe implicações diretas para a reorganização do território nessa parte do povoado, interferindo, inclusive na dinâmica de circulação da população local nas proximidades das praias.

A imagem de Pontal de Coruripe é frequentemente utilizada nos meios de divulgação e promoção turística, como sendo um ícone municipal. $O$ povoado possui um posto de informações turísticas e infraestrutura de orla, únicos no município de Coruripe. Parte significativa dos equipamentos de restauração está concentrada à beira-mar. Aliás, o mar historicamente exerce um papel de influência no cotidiano local, marcado pela tradicional atividade pesqueira que se faz presente até hoje, fazendo com que os barcos atracados sejam parte constituinte do cenário do lugar.

Além da pesca, outra característica marcante relacionada ao Pontal é a presença de casas de segunda residência nas ruas próximas ao mar, um reflexo do interesse de olhares externos, que marca não somente a paisagem, mas que também contribui para a formação do território de Pontal de Coruripe. Segundo Cruz (2002, p. 17) "o turismo concorre, no processo de transformação dos territórios para seu uso, com outros usos do território, bem como com formações socioespaciais precedentes ao seu aparecimento".

Antes do início do seu desenvolvimento turístico, esse antigo povoado de pescadores foi relatado no final da década de 1960, quando o pesquisador americano Shepard Forman, sobrevoando o litoral nordestino de helicóptero, escolheu o Pontal como objeto de investigação de sua pesquisa de doutoramento, a qual envolvia a temática da pesca artesanal ${ }^{2}$. Como resultado da convivência do pesquisador com o lugar, anos após o término da 
pesquisa, Forman retornou ao Pontal acompanhado de sua esposa Leona, que juntos em 1969 publicaram o Livro Bico: a Brazilian Raft fisherman's son, obra narrada em primeira pessoa que retrata cenas da vida do garoto Bico (então 10 anos de idade) e as características do cotidiano local na época. Por exemplo: "Pontal is so small you can find it only on very detailed maps of Brazil. There are just 200 houses and 852 people in Pontal - and most of those people are children [...]" (FORMAN, 1969, p. 17)3. Nesse período, Pontal de Coruripe não possuía água encanada, sua população utilizava um poço comunitário e a iluminação dependia de um gerador.

Atualmente, Pontal possui aproximadamente 3.560 habitantes (PSF ${ }^{4}$, 2015); o abastecimento e manutenção de água encanada são realizados pelo Departamento de Água e Esgoto Sanitário de Coruripe (DAESC). Porém, o povoado não possui sistema de esgotamento sanitário; por isso em praticamente todas as ruas percebe-se o esgoto escorrendo a céu aberto. Recentemente, no primeiro semestre de 2016, alguns trechos de ruas foram melhorados como resultado da ação do projeto Educar e Sanear, uma parceria entre a Petrobras e a Associação dos Moradores local.

A escola pública municipal de Pontal oferece serviços de creche e ensino fundamental para 784 alunos (matriculados no ano de 2015). O povoado possui um posto de saúde que funciona em horário comercial de segunda-feira a sexta-feira. O comércio local é caracterizado por lojas de pequeno porte, de setores como construção civil, confecção, alimentação, medicamentos etc., além dos serviços das pousadas, lanchonetes, bares, restaurantes e a venda de artesanato. Há também uma fábrica de gelo e uma pequena feira livre, que ocorre semanalmente às sextas-feiras pela manhã, com ofertas de produtos básicos de alimentação e confecção.

Um aspecto marcante do povoado, amplamente relatado por Forman (1969), e que resiste ao passar do tempo, é o artesanato da palha de Ouricuri, o qual expressa um traço da cultura popular pontalense, e que reflete o modo de vida local e a participação feminina na geração de renda e na forma de organização da comunidade. Ao se caminhar pelas ruas de Pontal facilmente se percebe o quanto a atividade está presente no contexto local, sendo comum artesãs exporem as peças de artesanato nas calçadas e nas janelas das casas. Atualmente, o artesanato também é comercializado em feiras especializadas e em centros receptivos de turistas da região, o que representa mudanças territoriais, partes das quais relacionadas ao turismo, com impactos na economia das artesãs.

\section{Ciclo de vida da área turística}

Em 1980, Richard W. Butler publicou o modelo do TALC, baseado na ideia de que os lugares turísticos são dinâmicos e que mudam com o passar do tempo. O modelo é fundamentado parcialmente no conceito de curva de venda e ciclo de vida do produto. O conceito de curva de venda explica que na fase inicial um produto é vendido de forma lenta, após, registra-se uma fase marcada pelo rápido crescimento, em seguida as vendas estabilizam e, posteriormente, declinam (BUTLER, 2006). 
O modelo de Butler permite a compreensão do processo de evolução do turismo em determinado lugar, através da identificação da(s) fase(s) em que o destino ou atrativo se encontra e as fases pelas quais passou. Do ponto de vista teórico e metodológico, o pesquisador pode agregar ao TALC de um lugar dimensões analíticas específicas, tais como dinâmica territorial do lugar, preço da terra, políticas públicas, desenvolvimento etc.

A demanda turística é responsável por moldar ou influenciar a oferta, assim, muitos destinos adaptam-se ao gosto de seus visitantes. Pesquisadores como Plog (1973) e Cohen (1972) são conhecidos na literatura especializada por terem desenvolvido pesquisas relacionadas à tipologia de visitantes. Viajantes com determinadas características psicográficas buscam destinos compatíveis com suas motivações e expectativas. Plog (1973) define que os viajantes se distribuem ao longo de um continuum que vai do psicocentrismo ao alocentrismo, ou seja, os que buscam contatos com ambientes familiares durantes as viagens e os que buscam novos ambientes, respectivamente.

\begin{abstract}
Em um dos extremos estão os "psicocêntricos," que tendem a ser ansiosos, inibidos, não afeitos a aventura e preocupados com os pequenos problemas da vida. Em contraste, os "alocêntricos" são autoconfiantes, curiosos, aventureiros e extrovertidos; de acordo com Plog, viajar é para eles um meio de expressar o seu caráter inquiridor e curioso (PEARCE, 2003, p.44).
\end{abstract}

$\mathrm{Na}$ parte central da escala de Plog, situam-se os viajantes meiocêntricos (ou mesocêntricos) que possuem características intermediárias, havendo meiocêntricos que podem ter uma inclinação maior para o psicocentrismo ou para o alocentrismo.

Outro pesquisador de tipologias de viajantes, Cohen (1972), estabelece a divisão dos tipos de turistas em quatro categorias: turista de massa organizado (viajam para destinos populares, através de pacotes turísticos programados e ofertados por operadoras); turista de massa individual (esse tipo se diferencia do primeiro, basicamante pela possibilidade de flexibilizar a programação durante a viagem); turista explorador (viaja sem a intermediação de agências, interessando-se mais por contatos com indivíduos do lugar visitado do que com outros turistas, buscando lugares pouco turistificados); além do turista errante (é o que pretende se incluir no destino como um próprio nativo, negando assim, a condição temporária de turista) (LOHMANN; NETTO, 2012).

Tem-se que o crescimento no número de visitantes é acompanhado de mudanças em sua composição, seguindo o padrão de passagem do alocentrismo para o psicocentrismo esboçado por Plog e outros pesquisadores para o turismo de massa institucionalizado, conforme sugerido por Cohen (1972) (PEARCE, 2003, p. 47). 
Nessa perspectiva teórica, o modelo de Butler prevê que inicialmente uma localidade turística recebe pequenos números de visitantes alocêntricos, restritos por carência de acesso, acomodações, e falta de conhecimento do local, mas à medida que instalações e condições de acesso são ofertadas ou melhoradas, o número de visitantes cresce e com a disseminação de informações através de campanhas de marketing e o aumento de facilidades aos viajantes, a área rapidamante se populariza (BUTLER, 2006), passando por alterações nas características da demanda:

\begin{abstract}
Assim, uma nova destinação turística será "descoberta" pelos turistas alocêntricos e, quando se torna mais conhecida e com maior e melhor infraestrutura turística e geral, passa a ser frequentada pelos mesocêntricos, que correspondem ao segmento quantitativo mais numeroso - geralmente chamado de turismo de massa (RUSCHMANN, 2010, p. 95).
\end{abstract}

Desse modo, o modelo evolutivo de Butler (1980) segue a perspectiva de que à medida que o tempo passa os destinos se alteram, e passam por fases caracterizadas por mudanças no perfil da demanda (em termos de número e tipos de turistas) e da oferta turística (atrativos, instalações, serviços etc.). Essas alterações marcam distintas fases no ciclo de vida da área turística (Figura 1).

Figura 1: Modelo do Ciclo de Vida da Área Turística.

Figure 1: Tourist area life cycle model.

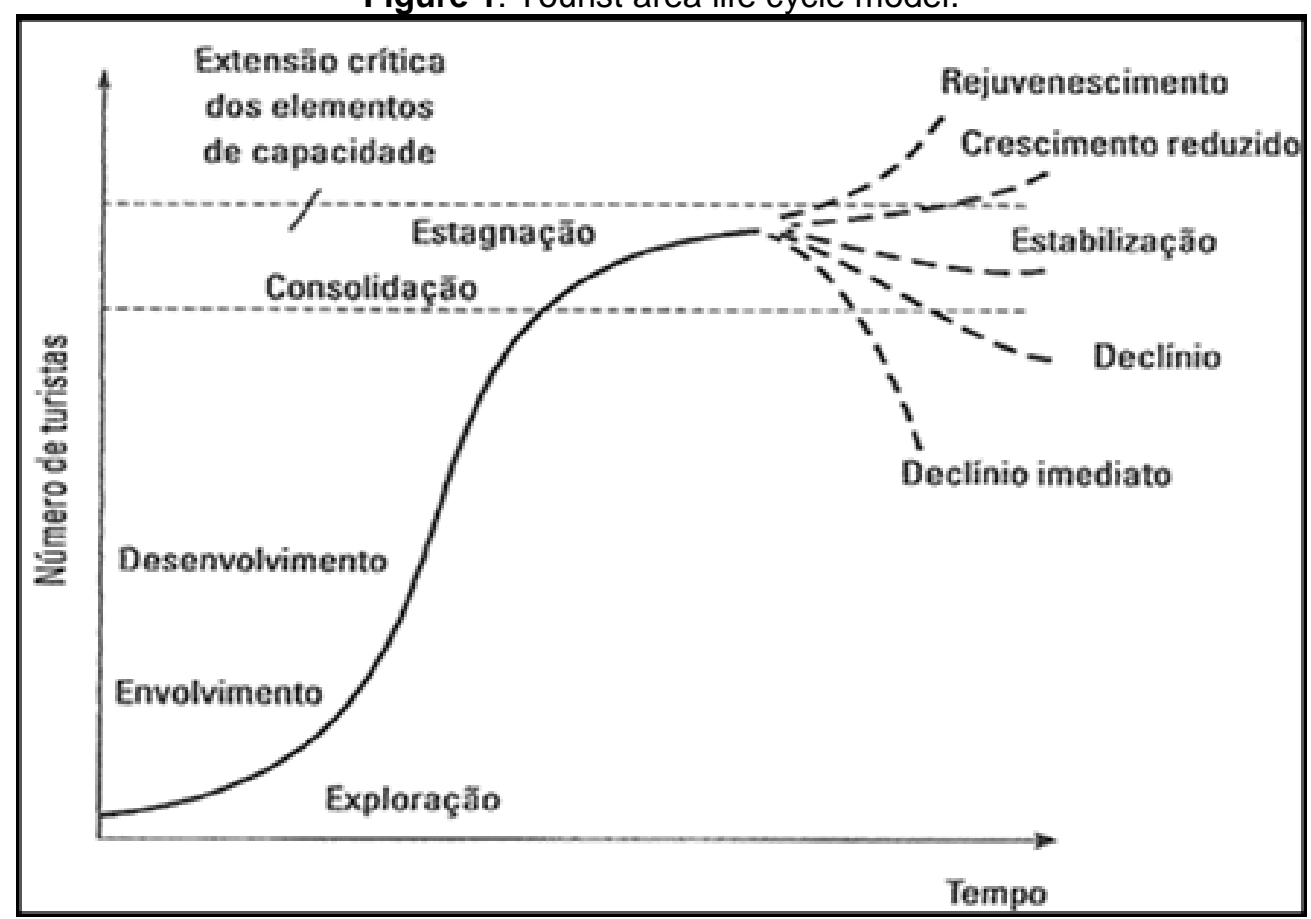

Fonte: Pearce (2003) redesenhada a partir de Butler (1980).

Source: Pearce (2003) adapted from Butler (1980). 
A partir de autores, como o próprio Bulter (1980) e Argarwal (1997); Pearce (2003) e Cooper et al. (1993), Araujo e Moura (2007), apresentam as características de cada fase que compõe o modelo de Butler (Quadro 1).

Quadro 1: Características das fases do Ciclo de Vida do Lugar Turístico.

Chart 1: characteristics of the phases of the tourist area life cycle.

\begin{tabular}{|c|c|}
\hline ESTÁGIO & CARACTERÍSTICA \\
\hline Exploração & $\begin{array}{l}\text {-A área começa a ser visitada por poucos turistas aventureiros. } \\
\text {-A área apresenta poucas facilidades públicas. } \\
\text {-Os turistas são de um único tipo - alocêntricos (PLOG, 1973). } \\
\text {-O patrimônio natural encontra-se bem preservado e, juntamente } \\
\text { com a cultura local, se constituem nos principais atrativos turísticos } \\
\text { do lugar. }\end{array}$ \\
\hline Envolvimento & $\begin{array}{l}\text { - Os residentes começam a oferecer serviços básicos aos turistas. } \\
\text { - O local começa a ser vendido como um lugar turístico. } \\
\text { - Emerge um período de alta temporada e correspondente pressão } \\
\text { sobre o setor público para a construção de infraestrutura. } \\
\text { - A maior parte dos serviços e negócios turísticos pertence aos } \\
\text { residentes. }\end{array}$ \\
\hline Desenvolvimento & $\begin{array}{l}\text { - número de visitantes ultrapassa a população residente na } \\
\text { estação turística. } \\
\text {-A maior parte dos serviços e negócios pertence a pessoas de } \\
\text { outras áreas. } \\
\text {-Início de antagonismo dos residentes aos turistas. } \\
\text { - Começam a surgir problemas ambientais, incluindo deterioração } \\
\text { dos equipamentos turísticos. }\end{array}$ \\
\hline Consolidação & $\begin{array}{l}\text {-O turismo se torna o principal segmento da economia local. } \\
\text { - Os equipamentos turísticos apresentam avançado grau de } \\
\text { deterioração. } \\
\text {-Os problemas ambientais se tornam visíveis. }\end{array}$ \\
\hline Estagnação & $\begin{array}{l}\text { - A área perde seu glamour inicial e sai da moda. } \\
\text { - A área começa a perder turistas para outras destinações. } \\
\text {-A área apresenta sérios problemas ambientais econômicos e } \\
\text { sociais. }\end{array}$ \\
\hline Pós-estagnação & $\begin{array}{l}\text {-A destinação entra em declínio gradual ou rápido. } \\
\text {-Pode surgir um processo de rejuvenescimento da área através de } \\
\text { investimentos na criação de novos atrativos, recuperação física da } \\
\text { área ou por meio de campanhas de marketing. } \\
\text { - Nesse estágio geralmente a situação ambiental encontra-se em } \\
\text { fase crítica. }\end{array}$ \\
\hline
\end{tabular}

Fonte: Araujo; Moura (2007, p. 98-99), baseados em Bulter (1980); Argarwal (1997); Pearce (2003) e Cooper et al. (1993).

Source: Araujo e Moura (2007, p. 98-99), compiled from Butler (1980); Argarwal (1997); Pearce (2003) e Cooper et al. (1993).

Desde 1980 até os dias atuais, o modelo de Butler vem sendo utilizado por diversos pesquisadores que o aplicaram em diferentes contextos. A curva em "S" não é um padrão de resultado, toda localidade estudada apresenta suas particularidades, inclusive na sequência e duração das fases. Cada destino ou atrativo possui singularidades que ao serem confrontadas com o turismo, suscitam formas variadas do seu processo de turistificação, e cada uma dessas formas funciona como fator que influencia o território. 
O TALC é uma ferramenta descritiva, que permite a visualização do histórico do turismo em determinado lugar, destinação ou atrativo, de sua evolução ao longo do tempo e, por conseguinte, possibilita a visualização prospectiva de possíveis cenários futuros, com ênfase no curto prazo. Dentre os aspectos que podem ser utilizados para se analisar o TALC de um determinado lugar turístico, as dimensões econômica, ambiental e social são de grande importância, pois sintetizam várias características contextuais do lugar. Neste estudo o ciclo de vida turístico de Pontal de Coruripe é investigado considerando as dimensões econômica e social, associadas à questão do território.

\section{Pontal de Coruripe: ciclo de vida turístico}

O interesse de olhares externos em Pontal de Coruripe teve início por meio de casas de segunda residência, fator que contribuiu para evidenciar o povoado no cenário regional. As fotografias feitas pelo casal Forman, aliadas aos dados obtidos por meio das entrevistas, permitem se afirmar que ainda na década de 1960 - quando Pontal possuía apenas 200 habitações (FORMAN, 1969), - já havia no lugar casas destinadas a tal função. Os visitantes vinham de localidades próximas, como da cidade de Penedo, e possuíam imóvel para desfrute durante o tempo livre.

Residências secundárias são comuns em localidades litorâneas nas quais o mar exerce a função de atração consequente das diversas possibilidades que o ambiente oferece, como lazer, tranquilidade, contato com diversos ecossistemas (praias, lagunas, dunas etc.), dentre outras. "No Brasil, o banho de mar começou a ser praticado no século $X X$, tornando-se hábito nos principais centros urbanos litorâneos, intensificando-se a partir da década de 1950" (FONTELES, 2004, p. 37). Essa situação não difere de muitas outras áreas litorâneas do Estado de Alagoas, nas quais as residências secundárias fazem-se presentes, e imbricam-se no processo de turistificação de localidades como Barra de São Miguel, Paripueira, Barra de Santo Antônio, além do próprio Pontal de Coruripe.

Em 1977, a publicação "Enciclopédia dos Municípios Alagoanos", ao descrever o município de Coruripe, no item "Turismo e folclore", pontua: "O município conta com inúmeros pontos turísticos de grande potencial. Citam-se a praia de Pontal do Coruripe, procurada por visitantes de toda a região [...]" (ENCICLOPEDIA... 1997, p. 147).

A cultura canavieira, historicamente presente no município de Coruripe, exerceu significativa influência no processo inicial de uso e ocupação do solo em Pontal por agentes externos a esse povoado, efetivamente por meio de residências secundárias pertencentes a pessoas vinculadas ao setor sucroalcooleiro. A ocupação inicial de espaços naturais privilegiados em Pontal ocorreu por usuários que possivelmente buscavam lazer e/ou proximidade com o local de trabalho. Esse tipo de uso estava relacionado a pessoas de classe social abastada que mantinham residência habitual em cidades que ofereciam maior oferta de serviços, e talvez também por trabalhadores especializados que detinham altos salários. 
Entretanto, os usineiros não foram os únicos segmentos sociais a terem Pontal como um lugar de refúgio. Houve naturalmente variação nos perfis dos proprietários, no entanto, visitantes originários de Arapiraca município mais importante do Estado de Alagoas depois de Maceió, localizado a $86 \mathrm{~km}$ de Pontal de Coruripe -, sempre se sobressaem nas falas dos entrevistados relacionadas a esse fluxo de pessoas para o Pontal:

"Aquela rua sempre foi assim, sempre foi daquele jeito, sempre foi na frente dos usineiros e atrás dos veranistas." P1 "Era moda o pessoal de Arapiraca vir pra'qui." [sic] P4.

A literatura especializada indica que uma residência secundária pode desempenhar outras funções para seus usuários. A discussão sobre os usos atrelados à atividade turística é evidente, não havendo consenso entre os pesquisadores, no sentido de se considerar o usuário de uma residência secundária enquanto turista ou não; e, por conseguinte, de se considerar uma residência secundária enquanto alojamento turístico ou não. "Na literatura existente atualmente, há muitas lacunas e contradições sobre a natureza da segunda residência e de seus usuários, chegando inclusive alguns autores a definir um novo tipo de turismo: o "turismo residencial" (FONSECA; LIMA, 2012, p. 13).

Nesse cenário, considerando as diversas possibilidades de uso de uma residência secundária, analisando o caso de Pontal de Coruripe, conclui-se que independente da função principal ou da motivação inicial de seus proprietários - lazer, trabalho, etc.- indubitavelmente a presença dessas casas, em dados momentos, serviram (também) como alojamento turístico, iniciando ou estimulando dessa forma, o processo de turistificação da localidade, como pode ser constatado por meio das falas dos entrevistados no Quadro 2:

Quadro 2: Uso das residências secundárias enquanto alojamento turístico.

Chart 2: Use of second homes as tourist accommodation.

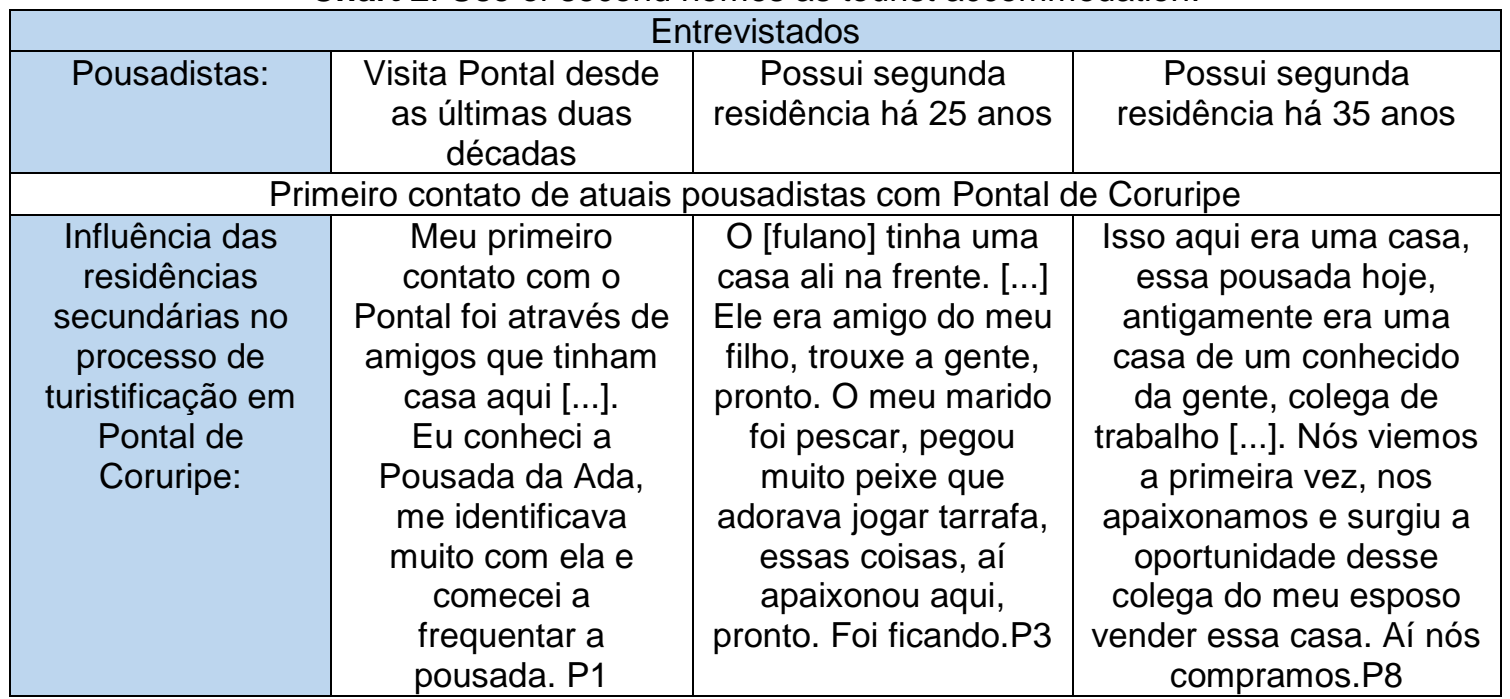

\section{Fonte: dados da pesquisa, 2016.}

Source: study data, 2016. 
Portanto, divergindo do previsto pelo modelo de Butler (1980), o ciclo de vida turístico de Pontal teve início com as segundas residências, que datam pelo menos da década de 1960. Possivelmente, os exploradores alocêntricos (PLOG, 1973) começaram a chegar a partir do início da década de 1980, e de forma não significativa. Em Pontal de Coruripe, as residências secundárias estimularam o processo de turistificação local, à medida que foram responsáveis pelo acolhimento não somente de seus proprietários, mas também, de novos usuários - nos quais se incluem turistas -, permitindo a experiência turística na localidade, inclusive em períodos anteriores à implantação de meios de hospedagem comerciais.

\begin{abstract}
E se o município de Coruripe é considerado uma das áreas mais paradisíacas do litoral Sul de Alagoas, onde praias como Lagoa do Pau, Pituba e Japú fazem a diferença, a beleza do Pontal de Coruripe, seu cartão postal, demorou a ser descoberto pela indústria hoteleira. Diferentemente da praia do Francês [...] o Pontal de Coruripe, a outra pérola turística do litoral Sul, atraiu primeiramente veranistas de Arapiraca e Sergipe, sobretudo pela beleza das praias e piscinas naturais de águas mornas, formadas pela barreira de recifes (BULGARELLI, 2012, p. 91).
\end{abstract}

Após esse período inicial do processo de turistificação do Pontal influenciado pelas residências secundárias, na década de 1980, teve-se a implantação dos dois primeiros meios de hospedagem comerciais, a saber: o Pontal Praia Hotel e a Pousada da Ada.

Mas a grande vocação do Pontal é mesmo turística. É lá que estão localizados o hotel Pontal do Coruripe, a pousada da portuguesa Ada e um majestoso aglomerado de casas de veranistas, três exemplos do embrião turístico que se esboça no município. "Durante os dois últimos verões nós conseguimos lotar completamente o hotel", orgulha-se Robledo Gomes, referindo-se à sua estrutura de 20 chalés, instalada na área mais alta do Pontal, classificada com duas estrelas pela Embratur e que conta com uma piscina com vista para o mar, restaurante, cavalos e charrete para passeios (MANOEL JUNIOR, 1991, s. p. grifo nosso).

Assim, constata-se neste estudo que o Pontal não teve as fases Exploração e Envolvimento bem caracterizadas, como é previsto teoricamente pelo modelo de Butler (1980), com o lugar despontando de forma mais clara como lugar turístico clássico, já com o início da fase Desenvolvimento, caracterizada pela implantação dos dois empreendimentos comerciais mencionados acima, inclusive um deles, a Pousada da Ada, de propriedade estrangeira. 
Implantado por um pontalense no ano de 1986, o Pontal Praia Hotel foi gerido por um parente do proprietário que possuía experiência anterior em hotelaria. Durante a entrevista, o empreendedor relatou que aos 22 anos de idade mudou-se para Maceió, onde residiu por mais de dez anos, e, ao retornar para Coruripe, viu a necessidade da implantação de empreendimentos no setor farmacêutico e hoteleiro. Segundo ele, o município tinha um grande potencial para esse tipo de comércio, pois apesar de não se ter condições favoráveis de acesso, havia um significativo fluxo de visitantes na década de 1980.

A italiana Ada Viganó desembarcou em Pontal de Coruripe pela primeira vez como mochileira em 1983 (ano provável). Considerando a classificação de Plog (1973) podemos dizer que se tratava de uma turista alocêntrica, que se programou para uma viagem de um ano pelo Brasil, e um dos destinos escolhidos foi Pontal de Coruripe. Porém, para Ada, o Pontal não foi somente mais um destino brasileiro: "[...] e depois não consegui ir embora porque o Pontal tinha sido um impacto tão forte que [...] era aqui que eu queria ficar".

Quando questionada sobre como ficou sabendo da existência de Pontal em uma época em que a comunicação não facilitava, tem-se a resposta:

\begin{abstract}
"Através de um livro, um guia turístico suíço que dizia: 'E se tiver tempo e não o sei o quê, de Penedo pra Maceió, entre no povoado idílico de pescadores, Pontal de Coruripe onde depois de comer um peixe frito na praia e contar uma mão cheia de estrelas, sonhará em nunca mais ir embora.' Pronto, e eu resolvi fazer isso. E cheguei aqui e quer dizer, independentemente do que tinha lido no livro, no guia, quer dizer, a sensação do déjà vu, de que era o meu lugar, que eu já conhecia isso, foi assim, amor à primeira vista mesmo".
\end{abstract}

O processo de implantação dos primeiros meios de hospedagem em Pontal de Coruripe coincide com os de outros destinos do litoral Sul alagoano, como Francês e Barra de São Miguel. Bulgarelli (2012) justifica tal coincidência como consequência da melhoria das condições de acesso por meio da abertura de estradas nessa parte do litoral de Alagoas.

De meados da década de 1980 até o final da década seguinte, a capacidade receptiva comercial de Pontal de Coruripe foi ofertada pelos dois primeiros meios de hospedagem, que até 1989 ofertavam 64 leitos, e a partir do ano de 1990 passaram por ampliações. Portanto, apesar de na década de 1980 se ter apenas dois empreendimentos, observa-se relativa diversificação, ao menos em termos de segmento, com oferta de produtos e serviços distintos entre si, e, por conseguinte, o atendimento de um público variado, o que se justifica se considerarmos o perfil e os fatores que motivaram os respectivos empresários. Em 1986 um pontalense caracterizado por ter espírito empreendedor, viu no turismo oportunidade de um bom investimento, enquanto que para a italiana Ada, implantar a pousada foi consequência da 
escolha de um novo ritmo de vida. Aos 40 anos de idade, Ada abandonou a carreira acadêmica e viu em Pontal a tranquilidade que buscava:

"Era o lugar perfeito, tranquilo em que eu queria morar. $\mathrm{E}$ fazer o quê? A única coisa era aliar turismo a qualquer coisa com o ensino, tanto que no primeiro ano, nos primeiros três anos na diária tinha uma aula de português pra os estrangeiros ou outro idioma, incluída".

Para o estudo do TALC, nesta investigação, considerou-se apenas a evolução dos meios de hospedagem comerciais de Pontal de Coruripe, ou seja, a partir do início da fase "desenvolvimento". Assim, não se inclui aqui a capacidade receptiva de residências secundárias, por não se ter dados quantitativos que possibilitem a mensuração do fluxo de turistas com base nas residências secundárias ao longo do tempo, além do fato que envolve a dificuldade de classificação de usuários de segunda residência enquanto turista ou não. E pela impossibilidade de se levantar dados sobre o número dos primeiros visitantes que começaram a chegar ao Pontal no início da década de 1980.

Em agosto de 1991, o suplemento publicitário da Revista Veja, em uma reportagem de José Manoel Junior (1991, s.p.), destaca o sucesso do setor econômico de Coruripe: "[...] uma economia forte coloca o município entre os quatro maiores em arrecadação de ICM, no Estado". As causas atribuídas ao mencionado sucesso são as tradicionais atividades da indústria sucroalcooleira e o desempenho satisfatório da Cooperativa Agrícola Pindorama. Neste sentido, o que o referido autor acrescenta é o trabalho desenvolvido pela "Aquicultura Capiatã, a maior fazenda de criação de camarão da Malásia, do mundo" (MANOEL JUNIOR, 1991, s.p.). Esse cenário produtivo teve reflexos diretos para a economia pontalense, pois a mencionada empresa tinha como função principal a criação de camarão de água doce, mas complementava suas atividades comprando camarão marinho direto de pescadores.

Lá em baixo a população local divide o espaço com os "estrangeiros". Se a Pousada da Ada notabilizou-se pela presença de europeus que procuram beleza e a tranquilidade de Coruripe, no Pontal, quem reina mesmo são os veranistas. Toda a região da orla é ocupada por pequenas mansões, na maioria pertencentes a plantadores de fumo de Arapiraca. Não é à toa que a Avenida paralela ao mar é conhecida pelo nome dessa cidade [...]. "O Pontal é tão bom que Arapiraca decidiu instalar uma filial aqui", brincam alguns veranistas (MANOEL JUNIOR, 1991, s. p.).

Assim, a marca das residências secundárias na paisagem de Pontal tornou-se evidente: "Pontal do Coruripe é uma vila de pescadores que, embora tenha sua arquitetura manchada por casarões de veraneio de um 
mau gosto típico de novo-rico, mantém seu charme e aconchego intactos" (BARCINSKI, 1996, p. 6). O autor ainda comenta sobre hábitos locais comunitários, como o fato comum de crianças brincarem nas ruas, e adultos se reunirem durante as tardes para conversas nas calçadas e à noite para assistir televisão na praça, além de que nesta época, o único telefone disponível era o do posto telefônico, "Esse telefone, aliás, é o elo de Pontal com o mundo" (BARCINSKI, 1996, p. 6).

O dia a dia pontalense segue impressionando o repórter paulista. Percebe-se o olhar do turista no cotidiano local quando a tradicional atividade pesqueira emerge aos seus olhos como atrativo:

\begin{abstract}
À tarde as jangadas e traineiras retornam da pesca, e a praia fica lotada de gente admirando os arabaianas, dourados, bagres, xaréus e as centenas de quilos de camarão que os pescadores tiram dos barcos. É um espetáculo maravilhoso, especialmente quando o Sol começa a se pôr (BARCINSKI, 1996, p. 6).
\end{abstract}

No ano seguinte, o também repórter Marcelo Amorim, destaca uma queda no número de turistas no povoado, fato que repercutiu diretamente em uma de suas principais atividades econômicas:

Os turistas não vão mais ao Pontal por falta de estrutura", disse a artesã Edite Ribeiro dos Santos. Ela lembrou que a falta de pavimentação da estrada que liga o povoado à rodovia AL-101 Sul fez com que as artesãs procurassem outros locais para vender os produtos. A artesã Maria Eleone dos Santos lamentou ter de passar por essa situação "Muitas vezes, a gente não negocia sequer uma peça e fica sem dinheiro para retornar para casa e até para comer", desabafou a artesã. Para tentar vender os produtos, as artesãs têm de ficar nas calçadas das casas dos moradores de Duas Barras, à espera dos turistas [ ...] (AMORIM, 1997, p. 45).

As falas das artesãs acima são claras demonstrações de total dependência financeira da atividade, passados quase 30 anos após o relato de Forman (1969), e neste aspecto, a situação pouco mudou, demonstrando que o cenário econômico local permaneceu restrito. A questão da dificuldade de venda do tradicional artesanato local não foi o único problema enfrentado pelas artesãs de Pontal nesse período. As transformações urbanísticas do lugar, o aumento da área habitada e mesmo o uso inadequado dos espaços naturais, gerou dificuldades de se encontrar a matéria prima para a produção do artesanato, ou seja, a palmeira Ouricuri.

Foi nesse contexto que se deu o crescimento da capacidade receptiva comercial de Pontal, por meio da implantação de dois novos empreendimentos, a saber: a Pousada Recanto do Pontal, em 1997, e a 
Pousada Mirante do Pontal, em 1999 (gráfico 1). Um fato em comum entre os dois empreendimentos é que ambos foram implantados por pessoas que já tinham vínculo com Pontal e que após se aposentarem resolveram instalar uma pousada, fixando-se de vez no lugar. Mais uma vez a tranquilidade a que o povoado remete nutriu a escolha do lugar como local fixo de moradia, intensificando e alterando as relações de antigos proprietários de residências secundárias com o lugar

Gráfico 1: Oferta de meios de hospedagem no período de 1985 a $1999^{5}$ Graphic 1: Offer of lodging facilities over the 1985-1999 period

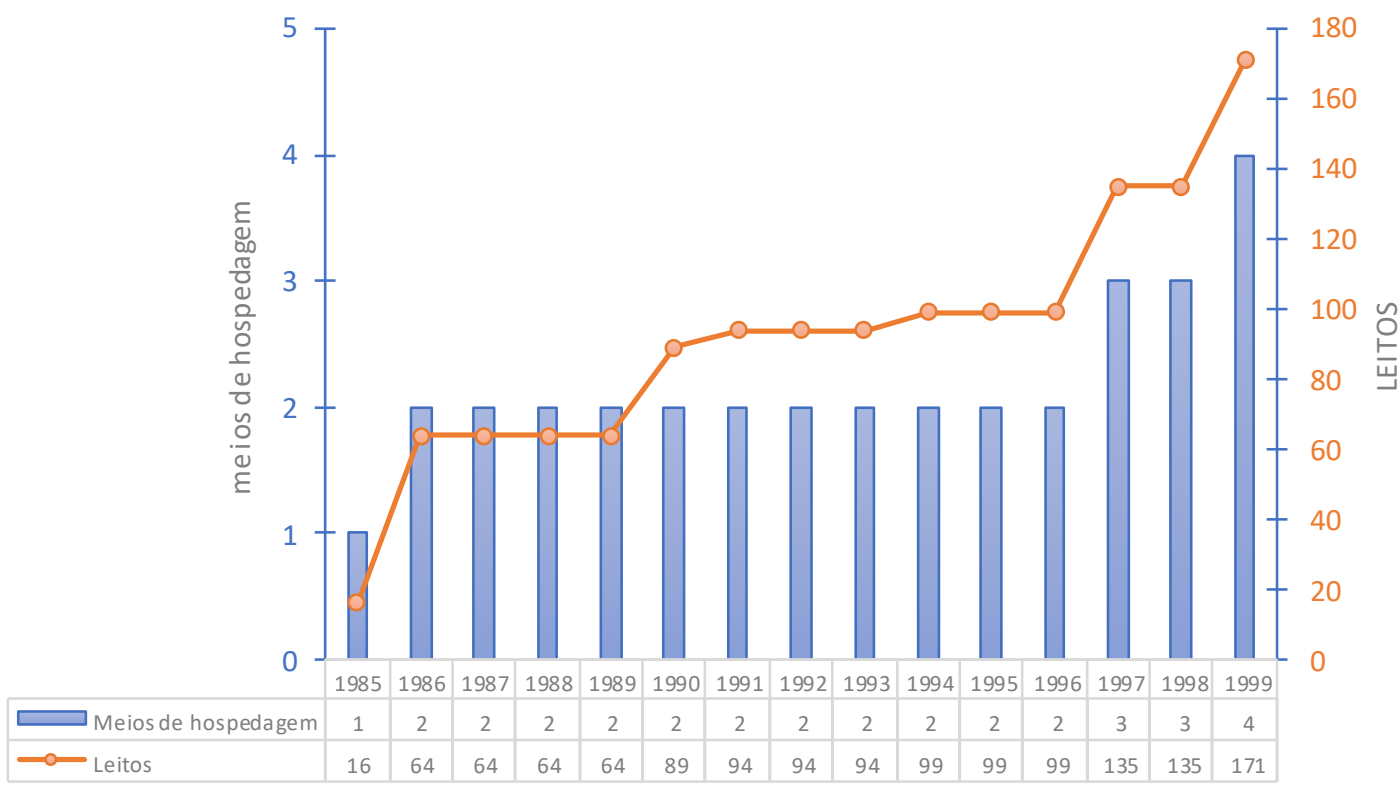

Fonte: elaborado com base em dados da pesquisa.

Source: study data.

No início dos anos 2000, a oferta de meios de hospedagem é incrementada por meio de um empreendimento diferenciado, com 19 chalés e 83 leitos A nova pousada se destacou no cenário local, tanto pela estrutura física quanto, principalmente, pela proposta de um ambiente com certo requinte, que lembra empreendimentos do tipo mini resorts, considerando a estrutura física e a proposta de autossuficiência em termos de serviços. "Assim nasceu a Pousada Paradise, a primeira pousada de luxo e charme do litoral sul de Alagoas" (BULGARELLI, 2013, p. 46).

No ano de 2006, teve-se mais um caso de proprietário de segunda residência que opta por investir no turismo em Pontal de Coruripe. O fator que motivou a abertura do empreendimento coincide com o histórico de outras pousadas. Por possuírem residência secundária no povoado há mais ou menos 25 anos, com o objetivo de se aposentar e passar mais tempo em Pontal, há 10 anos foi construída a pousada Pontal Pôr do Sol, a beira mar, com 10 chalés e 20 leitos.

No ano de 2008, a reportagem de Clevis Oliveira destaca o processo de urbanização da orla de Pontal. Após mencionar o fato histórico do 
naufrágio, supostamente no mar costeiro do atual município de Coruripe, do navio que transportava Dom Pero FernandesbSardinha para Portugal, seguese:

\begin{abstract}
Mais de quatro séculos depois, no Pontal de Coruripe pouco se fala sobre o assunto. É só chegar ao povoado para perceber que o ambiente tropical imprime outro ritmo de vida ao cotidiano de seus moradores. Apesar de já exibir características urbanas, a impressão é a que, ali, o tempo passa devagar - as pessoas não se furtam a "papear" e têm sempre um sorriso no rosto ao receber os visitantes (OLIVEIRA, 2008, p. 8).
\end{abstract}

Assim, no mesmo período de reurbanização da orla, com expectativas de trazer melhoras no setor turístico, um casal proprietário de supermercado construiu a Pousada Arapiraca, com seis UHs e 18 leitos, além de três apartamentos que nunca foram equipados, pois de acordo com a proprietária, o histórico de baixa demanda não justifica novos investimentos.

Em 2009, teve-se também a instalação da Pousada Canto de Yemanjá, localizada a beira mar, a mais próxima ao farol, com 10 UHs e 26 leitos, de propriedade de um arquiteto português, que por ser descendente de brasileiros sempre desejou conhecer o Brasil e o povo brasileiro e para isso implantou uma pousada em Pontal, porque inicialmente viu o povoado como um lugar tranquilo.

O tradicional Casarão de Pontal foi restaurado no período de 2007 a 2010. Mesmo durante esse período de restauro, a casa teve oferta de hospedagem, porém para um público mais restrito, e somente a partir de 2010 a casa oficializou-se como pousada, permanecendo até o ano $2014 \mathrm{com}$ oferta de seis UHs e 19 leitos. Após o período de um ano fechada, a pousada foi reaberta com nova gestão em 2015, não havendo alteração em termos de estrutura física e, portanto, de sua capacidade receptiva.

No ano de 2012, por consequência da divisão da Pousada da Ada entre os dois sócios proprietários, criou-se a Pousada Cinema, com seis UHs e 16 leitos; a pousada funcionou no período de novembro de 2012 a dezembro de 2015. De propriedade de um italiano que conheceu Pontal através de um amigo que também é empreendedor no local. O proprietário atribui a insustentabilidade financeira do negócio como a principal causa do fechamento, e salienta a deficiência em termos de divulgação e planejamento da atividade turística local.

Com base nesse histórico da oferta comercial de hospedagem ao longo dos últimos 30 anos, tem-se o gráfico 2, que aponta para um recente declínio, no período 2013-2015, mas que não é significativo, sendo o único período no qual houve algum declínio no histórico do processo de implantação de UHs em Pontal, desde 1985. 
Gráfico 2: Oferta de meios de hospedagens no período de 1985 a 2015.

Graphic 2: Offer of lodging facilities over the $1985-2015$ period.

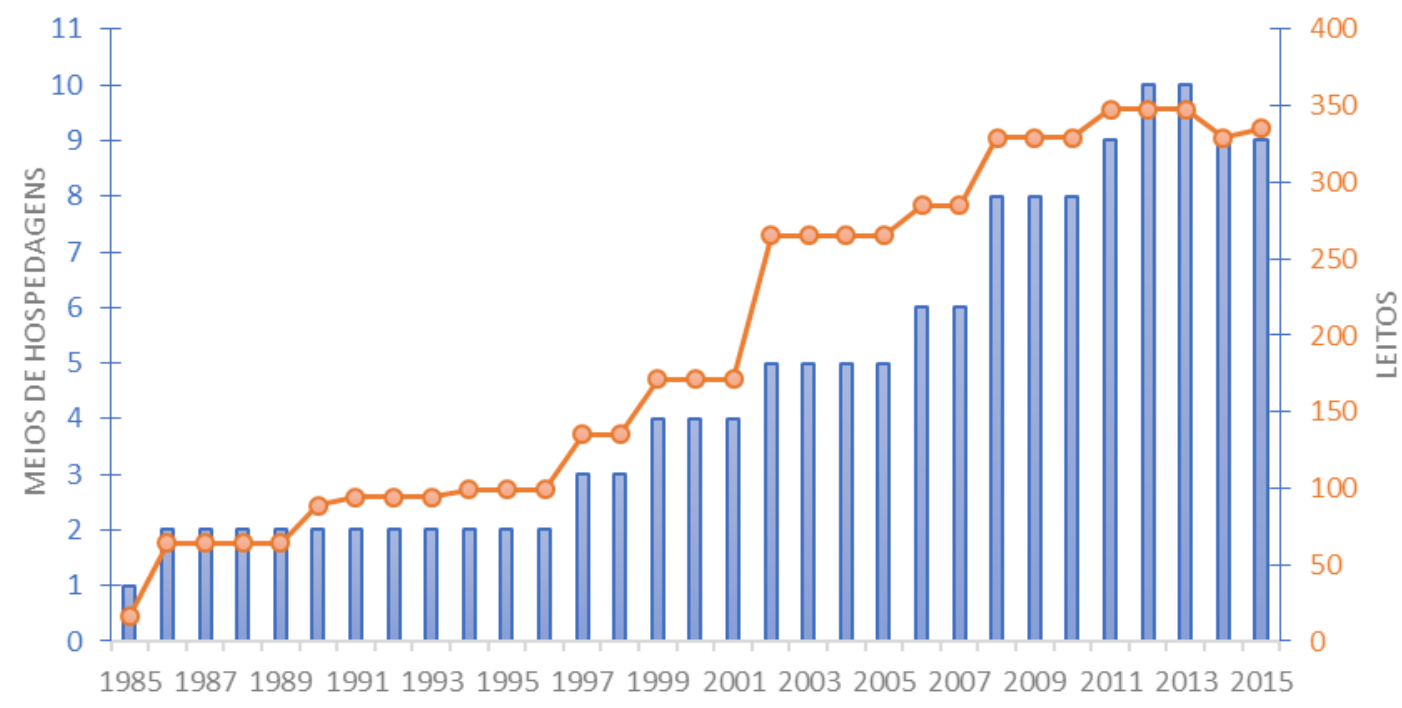

$\square$ Meios de hospedagens $\longrightarrow$-Leitos

Fonte: elaborado com base em dados da pesquisa.

Source: study data.

O estudo demonstra que os meios de hospedagem formais representam o principal fator que governou o TALC do povoado de Pontal de Coruripe. A decisão de construir as primeiras pousadas emergiu da experiência anterior de veranistas com o lugar, os quais, ao se aposentarem, queriam ao mesmo tempo morar e explorar economicamente o lugar com base no turismo. Assim, ao tempo em que o estudo de Pontal de Coruripe confirma o papel central desenvolvido pelo setor formal na constituição e evolução do ciclo de vida de um lugar turístico, ele também mostra que nem sempre haverá, de forma bem caracterizada, pelo menos a fase "exploração", formada por visitantes alocêntricos que, ao dar início à exploração de um lugar como visitantes, desencadeiam 0 início de um processo de desenvolvimento turístico tipificado teoricamente pelo TALC.

\section{Considerações finais}

Pontal de Coruripe teve o início de seu processo de turistificação marcado por residências secundárias e o consequente fluxo de visitantes que possivelmente difere do perfil alocêntrico esboçado por Plog (1973), considerando que no geral a hospedagem em uma residência secundária envolve a consequente pré-programação da viagem, com local de alojamento e alimentação definidos previamente, portanto, a fase inicial de Exploração proposta por Butler (1980), caracterizada por uma demanda de perfil explorador, em Pontal não ocorreu de forma intensa ou evidente, ou, pelo menos, não foi a primeira fase do ciclo evolutivo local.

Enquanto aumentava a atividade construtiva de residências secundárias, a partir de meados da década de 1980 se teve a implantação dos meios de hospedagem comerciais. Dos 10 empreendimentos 
pesquisados $^{6}$, apenas três tiveram mais explicitamente uma motivação comercial como justificativa primária para a sua implantação. $\mathrm{Na}$ fala dos demais sete empreendedores, verificou-se que a busca por qualidade de vida, traduzida pela tranquilidade que o lugar remete, foi um fator determinante para a permanência desses empreendedores no lugar, e o consequente desenvolvimento de uma atividade comercial no povoado.

Toda a oferta de hospedagem comercial, com exceção do primeiro proprietário do Pontal Praia Hotel, foi empreendida por agentes externos, ou seja, por não pontalenses, que, no entanto, escolheram o Pontal não somente como um ponto estratégico para o desempenho de uma atividade comercial, mas também como um lugar de moradia - fixa ou ocasional - o que levou a uma consequente criação de vínculos com o povoado.

Desse modo, considerando que os primeiros agentes empreendedores da oferta de hospedagem são externos, não houve também o que Butler classifica como fase de "envolvimento", na qual os residentes locais ao perceberam uma demanda turística, inicialmente originária de turistas exploradores (alocêntricos), iniciam a oferta de serviços básicos, os quais normalmente também inclui a oferta de hospedagem, porém com características informais e de pequeno porte.

Portanto, considerando a oferta de hospedagem, a fase de "envolvimento" não ocorreu plenamente em Pontal de Coruripe, o que se justifica, talvez, pelo histórico de dependência financeira de sua população de atividades de baixo rendimento, que ofereciam uma base permanente para a subsistência, como principalmente a pesca e a produção artesanal. No entanto, a fase de "envolvimento" por parte da população local, como é prevista pelo modelo de Butler, parece ter ocorrido por meio da oferta de serviços do setor de $A \& B$, sendo comuns relatos durante as entrevistas de que alguns pontalenses serviam refeições em suas próprias casas ou em quiosques na praia, com um cardápio marcado pela influência dos frutos do mar.

Desse modo, pode-se considerar que houve uma imbricação dos estágios propostos pelo modelo de Butler - se considerarmos também a inclusão dos serviços de A\&B. Enquanto a implantação dos meios de hospedagem formais caracterizou a fase de "desenvolvimento", no setor de A\&B a população local vivia a fase de "envolvimento".

Passados 30 anos desde a implantação do primeiro meio de hospedagem, Pontal, atualmente com 335 leitos disponíveis, tem carências de infraestrutura, sendo comuns reclamações no que se refere à baixa qualidade do fornecimento de energia elétrica, a presença de lixo nas praias, e o esgoto não tratado correndo a céu aberto pelas ruas do povoado. A ocupação de áreas privilegiadas por meio da construção de casas reduziu drasticamente o acesso ao mar, tendo o lugar três pontos principais de acesso, além de dois becos estreitos entre as casas de veraneio. Durante a maré alta, não se tem área de praia disponível para o visitante ou residente, devido ao avanço do mar, que também provocou significativas alterações no lugar desde a década de 1980 aos dias atuais, inclusive ocupando antigas áreas habitadas por meio da erosão marinha. 
O barulho, consequente de veículos automotores em períodos tradicionais de tempo livre, é sentido por alguns dos pousadistas como algo prejudicial ao desenvolvimento de seus empreendimentos. A baixa ocupação hoteleira nas estações de outono e inverno é outro ponto de reclamação, fato histórico e comum em destinos de sol e mar desprovidos de um planejamento responsável da atividade turística. A descontinuidade de eventos, sempre mencionada nas falas dos pousadistas locais, confirma e salienta tal deficiência.

Desse modo, o mar e os cenários litorâneos associados, como fatores de atração principais, parecem ter sido exaustivamente alterados em Pontal, tanto pelo avanço do mar quanto pela forma de apropriação do espaço, não havendo assim, a visualização de novas possibilidades de usos, a não ser, por meio de uma requalificação.

Não há em Pontal atualmente sustentabilidade econômica no uso das instalações hoteleiras, que permanecem ociosas durante parte significativa do ano. O momento atual se traduz em uma visão pessimista por parte dos pousadistas, que reclamam da baixa ocupação sentida principalmente nos últimos anos e a consequente insustentabilidade financeira dos empreendimentos. Portanto, o destino parece apontar para o início de uma fase de "declínio", não havendo no histórico de seu ciclo de vida marcas de uma diversificação da oferta, que sempre esteve ligada às belezas naturais. As perspectivas de futuro de atuais gestores com relação a continuidade de investimento no setor turístico não são positivas. O mesmo vínculo com o lugar que determinou para alguns a implantação do meio de hospedagem determina também sua resistência atual enquanto empresa, que do ponto de vista financeiro, não favorece ou justifica a continuidade do negócio.

\section{Referências}

ALAGOAS (Estado). SECRETÁRIA DE ESTADO DO DESENVOLVIMENTO ECONÔMICO E TURISMO- SEDETUR. Lagoas e mares do sul - Coruripe. Disponível em: <http://www.sedetur.al.gov.br/conhecendoalagoas/regioes/lagoas-e-mares-do-sul> Acesso em: 20 jul. 15.

AMORIM, M. Comunidades não se beneficiam com o turismo. Gazeta de Alagoas. Maceió, 05 out. 1997. Interior. Caderno A, p. 45.

ARAUJO, L.M.; DREDGE, D. Tourism development, policy and planning in Brazil. In: LOHMANN, Guilherme; DREDGE, Dianne (Eds.). Tourism in Brazil: environment, management and segments. London: Routledge, 2012, p. 17-29.

ARAUJO, L.M.; MOURA, F.B.P. A expansão do turismo na zona costeira nordestina: crescimento econômico, degradação ambiental e erosão cultural. In: CORIOLANO, L.N.M.T.; VASCONCELOS, F.P.(Orgs.). 0 turismo e a relação sociedade-natureza: realidades, conflitos e resistências. 1 . ed. Fortaleza: EDUECE, 2007, p. 94-114. 
BARCINSKI, A. Férias à margem das alagoas. Pontal do Coruripe, a praia mais linda do planeta. Jornal da tarde - SP. São Paulo, 10 de nov. 1996. Turismo. Caderno E, p. 6.

BULGARELLI, C. História da Hotelaria em Alagoas. Maceió, AL: Ed. Ideias de Comunicação/gráfica Jaraguá, 2012.

BULGARELLI, C. Livro de Ouro da hotelaria alagoana: a história dos melhores meios de hospedagem do Estado de Alagoas. 1. ed. Maceió, AL: Ed. Ideias de Comunicação/gráfica Jaraguá, 2013.

BUTLER, R.W. (Org.). The tourism area life cycle: applications and modifications. v.1, Aspects of tourism. England: Channel View Publications, 2006.

COHEN. E. Towards a sociology of internacional tourism. Social Research, v. 39, 1972, p. 31-46.

CRUZ, R.C. Política de turismo e território. 3. ed. São Paulo: Contexto, 2002.

DIÉGUES JÚNIOR, M. (1912-1991) O banguê nas Alagoas: traços da influência do sistema econômico do engenho de açúcar na vida e na cultura regional. 3. ed. Maceió: Edufal, 2006. (Coleção nordestina).

ENCICLOPÉDIA DOS MUNICÍPIOS ALAGOANOS. Planejamento e orientação: Hilton C. Mota. Editor: Sidney Soares. Maceió: SERGASA Serviços Gráficos de Alagoas S/A, 1977. (Fotolito: James Antonio Pinto Alves; Antonio dos Santos).

ENCICLOPÉDIA MUNICÍPIOS DE ALAGOAS. Coordenação geral: Leonardo Simões. 3. ed. Maceió: Instituto Arnon de Mello, 2012.

FONSECA, M.A.P.; LIMA, R.M.M. Segunda residência: conceito, características e significados. In: FONSECA, M.A.P. (Org). Segunda residência, lazer e turismo. Natal, RN: EDUFRN, 2012.p. 11- 18.

FONTELES, J.O. Turismo e impactos socioambientais. São Paulo: Aleph, 2004.

FORMAN, L.S. Bico: a Brazilian Ralf fisherman's son. New York: Lothrop, Lee \& Shepard, 1969.

INSTITUTO BRASILEIRO DE GEOGRAFIA ESTATÍSTICA (IBGE) Cidades@/ Coruripe. Disponível em: $<$ http://www.cidades.ibge.gov.br/xtras/perfil.php?lang=\&codmun=2702306> Acesso em: 15 de abr. 2015.

LOHMANN, G.; NETTO, A.P. Teoria do turismo: conceitos, modelos e sistemas. 2. ed. ampl. e atual. São Paulo: Aleph, 2012.

MANOEL JUNIOR, J.C. Turismo, desenvolvimento e harmonia social. Veja 28 graus. Suplemento publicitário da revista Veja. 28 de agosto de 1991. (Fotos: Freire).

OLIVEIRA, C. Descubra o charme do Pontal de Coruripe. Gazeta de Alagoas. Maceió, 11 de jan. 2008. Fim de Semana. Encantos do litoral. Caderno B, p. 8. 
PEARCE, G.D. Geografia do turismo: fluxo e regiões no mercado de viagens. São Paulo: Aleph, 2003.

PLOG, S.C. Why destination areas rise and fall in popularity. Cornell Hotel and restaurant administration Quarterly. November, 13-16, 1973.

RUSCHMANN, D. Turismo e planejamento sustentável: a proteção do meio ambiente. 15. ed. São Paulo: Papirus, 2010.

SILVA, P. Orgulho ou vergonha? O Mané do Rosário: manifestação do patrimônio cultural intangível de Poxim, Coruripe, AL, Brasil. Pasos Revista de Turismo y patrimônio cultural. Vol. 11, N.르 2, págs. 343-350, 2013.

USINA CORURIPE. Disponível em: <http://www.usinacoruripe.com.br> Acesso em: 20 set. 2015.

\section{Notas}

Este artigo é baseado em uma dissertação do Programa de Pós-graduação em Arquitetura e Urbanismo, Mestrado em Dinâmicas do Espaço Habitado, da Universidade Federal de Alagoas (UFAL).

${ }^{1}$ Dados obtidos em abril de 2016, através da pesquisa de campo realizada com os empreendimentos de hospedagem de Pontal de Coruripe.

${ }^{2}$ Forman, Shepard. The raft fishermen: tradition and change in the Brazilian peasant economy. Bloomington: Indiana University Press, 1970.

${ }^{3}$ Pontal é tão pequeno que só pode ser localizado em mapas do Brasil muito detalhados. Há apenas 200 casas e 852 pessoas em Pontal - dessas, a maioria é formada por crianças (tradução livre).

${ }^{4}$ Programa de saúde da família, Povoado Pontal de Coruripe, AL, Brasil. Nov. 2015.

51990: ampliação de oito UHs (25 leitos) no Pontal Praia Hotel; 1991: ampliação duas UHs (cinco leitos) da Pousada da Ada; 1994: ampliação duas UHs (cinco leitos) da Pousada da Ada.

${ }^{6}$ Foram realizadas 11 entrevistas, sendo nove com representantes de meios de hospedagem ativos, um inativo, além do antigo proprietário que implantou o Pontal Praia Hotel. 
Priscylla Maria Ferreira da Silva: Universidade Federal de Alagoas, Maceió, AL, Brasil.

E-mail: priscylla.tur@gmail.com

Link para o currículo Lattes: http://lattes.cnpq.br/5180752519254404

Lindemberg Medeiros de Araujo: Universidade Federal de Alagoas, Maceió, AL, Brasil.

E-mail: Imedeirosbr@gmail.com

Link para o currículo Lattes: http://lattes.cnpq.br/1427075376799452

Silvana Pirillo Ramos: Universidade Federal de Alagoas, Maceió, AL, Brasil.

E-mail: silvanapirillo@uol.com.br

Link para o currículo Lattes: http://lattes.cnpq.br/2886313019289301

Data de submissão: 29 de maio de 2018

Data de recebimento de correções: 03 de junho de 2018

Data do aceite: 03 de junho de 2018

Avaliado anonimamente 